\title{
A single-step purification of the glycoprotein of Nipah virus produced in insect cells using an anion exchange chromatography method
}

\begin{abstract}
A single-step purification method based on an anion exchange chromatography was developed to purify truncated Nipah virus glycoprotein (tNiVG) expressed in Spodoptera frugiperda 9 (Sf9) insect cells. The preferred buffer conditions to bind and elute tNiVG protein were $50 \mathrm{mM}$ sodium carbonate with $\mathrm{pH} 9$ and $50 \mathrm{mM}$ sodium citrate with $\mathrm{pH} 5$, respectively. The use of elution buffer without sodium chloride separated the tNiVG protein from the tightly bound major host proteins and subsequently avoided the desalting step as one of the further downstream processes. About $90 \%$ purity and $89 \%$ recovery of tNiVG protein were achieved with the developed purification method.
\end{abstract}

Keyword: Anion exchange chromatography; Enzyme-linked immunosorbent assay; Mass spectrometry; Spodoptera frugiperda 9; Truncated Nipah virus glycoprotein 